\title{
INFLUENCE OF SERVICE EXCELLENCE ON CONSUMER SATISFACTION OF RIDESHARING INDUSTRY
}

\author{
Ahmed Ziyad ${ }^{1}$, Zia-Ur-Rehman ${ }^{2}$, Zahara Batool ${ }^{3}$, Ammad Hassan Khan ${ }^{4}$ \\ 1,2,4 Department of Transportation Engineering and Management, University of Engineering \\ and Technology, Pakistan \\ ${ }^{3}$ Institute of Transport Studies, University of Leeds, United Kingdom
}

Received 11 July 2020; accepted 22 August 2020

\begin{abstract}
The objective of the study was to determine the influence of service excellence on consumer satisfaction in the ridesharing industry of Pakistan. Uber and Careem are two ridesharing services or Transport Network Companies (TNCs) which use mobile-based applications and use GPS to connect passengers and drivers in an efficient way. These ridesharing companies have been operating in the country for the past five years. For TNCs such as Uber and Careem, consumer satisfaction plays an important role in retaining customers and satisfying them thereby boosting their profits. Consumer satisfaction and service excellence are interconnected and associated with each other. This research determined the influence of the five service quality dimensions of SERVQUAL model i.e. assurance, responsiveness empathy, tangibility and reliability on consumer satisfaction of ridesharing services. This questionnaire survey-based research study was carried out on 268 respondents. The collected data was analyzed by Pearson correlation followed by the formulation of the regression model, associating consumer satisfaction with service quality. The research showed that all the service quality dimensions had a positive impact on consumer satisfaction. Assurance, responsiveness, and empathy significantly influenced consumer satisfaction whereas reliability and tangibility had a less significant impact on consumer satisfaction as compared to other service quality parameters. This research study assisted the TNCs in better understanding of service quality parameters which needed improvement for enhancing the consumer satisfaction.
\end{abstract}

Keywords: consumer satisfaction, ridesharing, service quality, Transport Network Companies (TNCs).

\section{Introduction}

Technological advancements and innovations in information technology have completely changed the way people commute now a day. The concept of ridesharing companies has been introduced in various regions of the world. These Transport Network Companies (TNCs) such as Uber and Careem, utilize a unique business model in which drivers are hired as private contractors using their personal cars for ridesharing and connected to the passengers via online platforms i.e. mobile-based apps. The advent of ridesharing companies has resulted in a tough competition with existing taxi market. People prefer using ridesharing apps for commuting based on their reliability and fare economy. In the taxi industry and law enforcement authorities, TNCs were not

${ }^{1}$ Corresponding author: ahmed.ziyad@idap.pk 
welcomed with that much warmth since these companies reduced the market share of taxi industries and operated in the absence of appropriate regulatory frameworks.

Despite the resistance from the taxi market and law enforcement authorities, ridesharing companies continued to become popular among consumers. In order to dominate share of the taxi industry, ridesharing companies have to continuously improve their service excellence and quality. The resulting enhanced consumer satisfaction will increase the likelihood of the companies to retain and make new customers. Service quality can be measured using different dimensions. In the past, SERVQUAL Model service quality dimensions have been used widely for measuring service excellence in different industries. It measures service quality using five dimensions. Since consumer satisfaction is directly related to service quality hence it can be easily measured using the service quality parameters of SERVQUAL. The results of the service quality assessment may help ridesharing applications in determining their existing consumer satisfaction and later on, utilize it to improve the perceived service quality.

The research study identifies the effect of service excellence on consumer satisfaction using the SERVQUAL service quality parameters. The survey-based study comprises of 268 participants belonging to Lahore (a City of Pakistan). This quantitative research uses statistical analyses to identify parameters related to level of service which play a noteworthy role in determining consumer satisfaction.

\section{Literature Review}

Advancements in cellular technologies accompanied by global positioning systems
(GPS) have introduced ridesharing or ridehailing platforms to a number of consumers (OECD, 2018). Ridesharing companies, also known as online transportation services, are such individual transportation services in which the consumer can order or book a ride by using the mobile-based app and the driver of the vehicle can also respond to the ordered or booked ride by using the corresponding mobile-based apps (Wallsten, 2015). Alberta's Ministry of Transportation defines these apps as Transport Network Companies i.e. the firms which provide services of prearranged trips to passengers by connecting them to drivers using their personal vehicles, using online mobile-based apps (Government of Alberta, 2019).

Consumer satisfaction can be defined as the way in which a user perceives certain service or product in either satisfactory or dissatisfactory way based on the expected standard or performance of that service or product (Kotler \& Keller, 2006). According to (Oliver, 1980), consumer satisfaction is derived from the service assessment and in turn, it can end up in satisfying customer in case of positive assessment and dissatisfying customer in case of negative assessment. Consumer Satisfaction is an output of service quality perceived at the customers' end ( $\mathrm{Su} \&$ Huang, 2016). In short, it can be concluded that consumer satisfaction and service excellence or quality are interconnected and associated.

Service quality is the collation of perceived performance and the expected performance (Oliver et al., 1994). It can also be defined as an expectancy-disconfirmation paradigm, arising from the difference of expected and perceived performance of service (Parasuraman et al., 1985). When it comes to the performance assessment of $\mathrm{m}$-commerce 
based services, service excellence plays an important role (Salameh \& Hassan, 2015). Customer behaviors, customer satisfaction, and customer loyalty are closely related to service excellence. Good service quality has a contructive influence on consumer satisfaction (Spreng \& Mackoy, 1996).

In Pakistan, based on the limited public transport options available, the preferred choice of regular commuters is a privatelyowned vehicle or motorbike. The emergence of mobile app-based ridesharing companies has turned out to be a widely opted mode of transportation in the taxi market of Pakistan. As of now, two main ridesharing companies i.e. Uber and Careem, are operating in Pakistan. In March 2019, Careem became a wholly-owned subsidiary of Uber, operating as an independent company under the same name i.e. Careem (Careem, 2019). Development of a viable advantage over the rival companies is crucial for ridesharing companies. For TNCs, it is a need of the hour to continuously improve their service quality. According to Caro and Garcia (2007), measuring service quality can lead to long term success and for the service providers, it can result in providing a significant advantageous edge over rivals. This makes service quality a defining element in assessing consumer satisfaction. Patterson recommends consumer satisfaction to be regularly measured and evaluated so that service providers can maintain a competitive advantage in their relevant markets (Patterson, 1993).

A service quality model known as SERVQUAL has been extenively applied by analysts in assessing level of service. Originally, SERVQUAL comprised of ten service quality dimensions i.e. reliability, responsiveness, competence, access, courtesy, communication, credibility, security, understanding consumer and tangibles. Later on, the dimensions of SERVQUAL Model were refined and reduced from ten to five i.e. reliability, responsiveness, tangibles, assurance, and empathy. It is also known as RATER Model (Parasuraman et al., 1985). Parasuraman's SERQUAL Model defines the service quality as the gap which exists between the expected and perceived service quality at the customer's end (Parasuraman et al., 1988). In the context of ridesharing companies, considering RATER Model, tangibility stands for substantial facilities of the ridesharing services such as the condition of vehicles and mien of drivers. Reliability is associated with the capability to provide the guaranteed ridesharing services meticulously. Responsiveness is a predictor of how willingly ridesharing companies and drivers want to serve consumers and deliver instant services. Assurance is indicative of the level of comprehension and behavior depicted by the drivers of the ridesharing companies and their ability to develop consumer's reliance and belief. Empathy accounts for presentation of discrete heed to the consumers by ridesharing companies.

In literature, the SERVQUAL model has been criticized as being based on perception. According to (Buttle, 1996), SERVQUAL has been used by several researchers in measuring service quality in various sectors such as banking, restaurants, airline, etc. As outlined by (Saravanan \& Rao, 2007), consumer satisfaction is defined by the level of the service quality provided by the service providers. In the SERVQUAL 
Model, the author has also tried the same i.e. to relate consumer satisfaction with service excellence.

The review of the literature reveals that in the past, several researchers have worked in ridesharing and taxi industry for determining consumer satisfaction through various service quality parameters. Horsu and Yeboah (2015) examined the relationship and effects of service quality on consumer satisfaction in taxi services, using RESCA model i.e. reliability, continuous service, safety, comfort, affordability and driver behavior. An exploratory study done on Indian Taxi Industry identified various factors affecting consumer satisfaction such as driver professionalism, car condition and convenience (Khan et al., 2016). In October 2016 , research was conducted on local taxi companies of Vietnam for identifying factors affecting customer satisfaction and customer loyalty using SERVQUAL and IDCTP Models (Khuong \& Dai, 2016).

Kumar and Kumar (2016) studied the relationship between innovativeness, price consciousness and coupon redemption behavior among cab services of India. The research was also conducted on the ridesharing industry of Malaysia for identifying factors affecting service quality on consumer satisfaction. It was found out by researchers that tangible, reliability, price, promotion and coupon redemption and comfort had a positive effect on consumer satisfaction (Balachandran and Hamzah, 2017). In 2017, Sharma and Das identified the effect of service quality dimensions on consumer satisfaction in online cab industry of India, using the SERVQUAL Model. The research concluded that all the dimensions of service quality in SERVQUAL Model i.e. tangibles, responsiveness, empathy, reliability, and assurance, play a vital role in determining consumer satisfaction (Sharma \& Das, 2017).

Using twenty service quality dimensions, (Silalahi et al., 2017) analyzed the service quality of the online transportation services of GO-JEK, Indonesia. Research work carried out in Yamamah University, Riyadh, Kingdom of Saudi Arabia, evaluated the consumer satisfaction in users of taxi services using mobile applications by five performance measures i.e. mobile app convenience, driver's attitude, time reliability price affordability and car condition (Sajid et al., 2018). In Pakistan, an empirical analysis of ridesharing applications was conducted in Karachi for assessing the quality of ridesharing services (Ahmed \& Burki, 2018). Research on consumer satisfaction of ridesharing services within Lahore city revealed that convenient use of the mobile app, driver behavior, time reliability, and price affordability had a significant effect on consumer satisfaction (Rasheed et al., 2018). From literature, it could be concluded that a study was needed to identify the influence of service excellence on consumer satisfaction of ridesharing industry in Pakistan using different service quality dimensions.

\section{Research Objectives}

The objective of this research was to study the influence of service excellence or quality on consumer satisfaction of ridesharing companies i.e. Uber and Careem. Identification of various service quality factors influencing consumer satisfaction in ridesharing services would assist the TNCs in improving their existing service quality. It would also narrow down the areas of interest for transport officials to consider while developing ridesharing regulatory frameworks. 


\section{Research Methodology}

Questionnaire-based surveys were carried out for the research study. The population consisted of users of the ridesharing services i.e. Uber and Careem, belonging to the second populous city of Pakistan i.e. Lahore. Non-probabilistic convenience sampling technique was deployed while carrying out surveys. Questionnaires were handed over to TNCs' drivers to be filled in by passengers (ridesharing users) during rides. Responses from the general public were also recorded and included in the database of responses.

The sample size was determined using Cochran's formula (Kotrlik and Higgins, 2001). The desired level of confidence was taken equal to $95 \%$ and precision was taken as $6 \%$. Maximum variability was assumed for yielding maximum sample size and the standard deviation was taken as 0.50 . Based on the aforementioned parameters, the adopted sample size was 268. Maximum variability for obtaining the maximum sample was assumed to generalize the results to the population under consideration, more authentically.

The service quality dimensions to assess consumer satisfaction were selected from the SERVQUAL model. The five parameters of the SERVQUAL model which determined the service excellence were reliability, assurance, tangibility, empathy, and responsiveness, also known altogether as RATER. For assessing the consumer satisfaction from RATER service quality parameters, each parameter was associated with three performance measures as shown in Figure 1. Consumer satisfaction was also associated with three performance measures. The questionnaire was based on the performance measures corresponding to each RATER dimension and consumer satisfaction, as presented in Figure 1.

It comprised of total twenty-four questions out of which six were based on demographic characteristics of respondents, fifteen were related to five service quality dimensions i.e. reliability, assurance, tangibility, empathy and responsiveness, and three questions were associated with overall consumer satisfaction. The primary data was recorded in the form of the responses from the ridesharing users. The answers of respondents were recorded by using a Likert type scale ranging from 1 to 5 ("Strongly disagree" to "Strongly agree").

Reliability test was conducted on data received from the first 30 respondents for a consistency check of the questionnaire. After that, Pearson Correlation Analysis was carried out on the complete data set of 268 respondents. In the end, regression analysis was carried out to formulate a regression model correlating service quality factors with consumer satisfaction. IBM Statistics Software 24 was used for statistical analysis. 


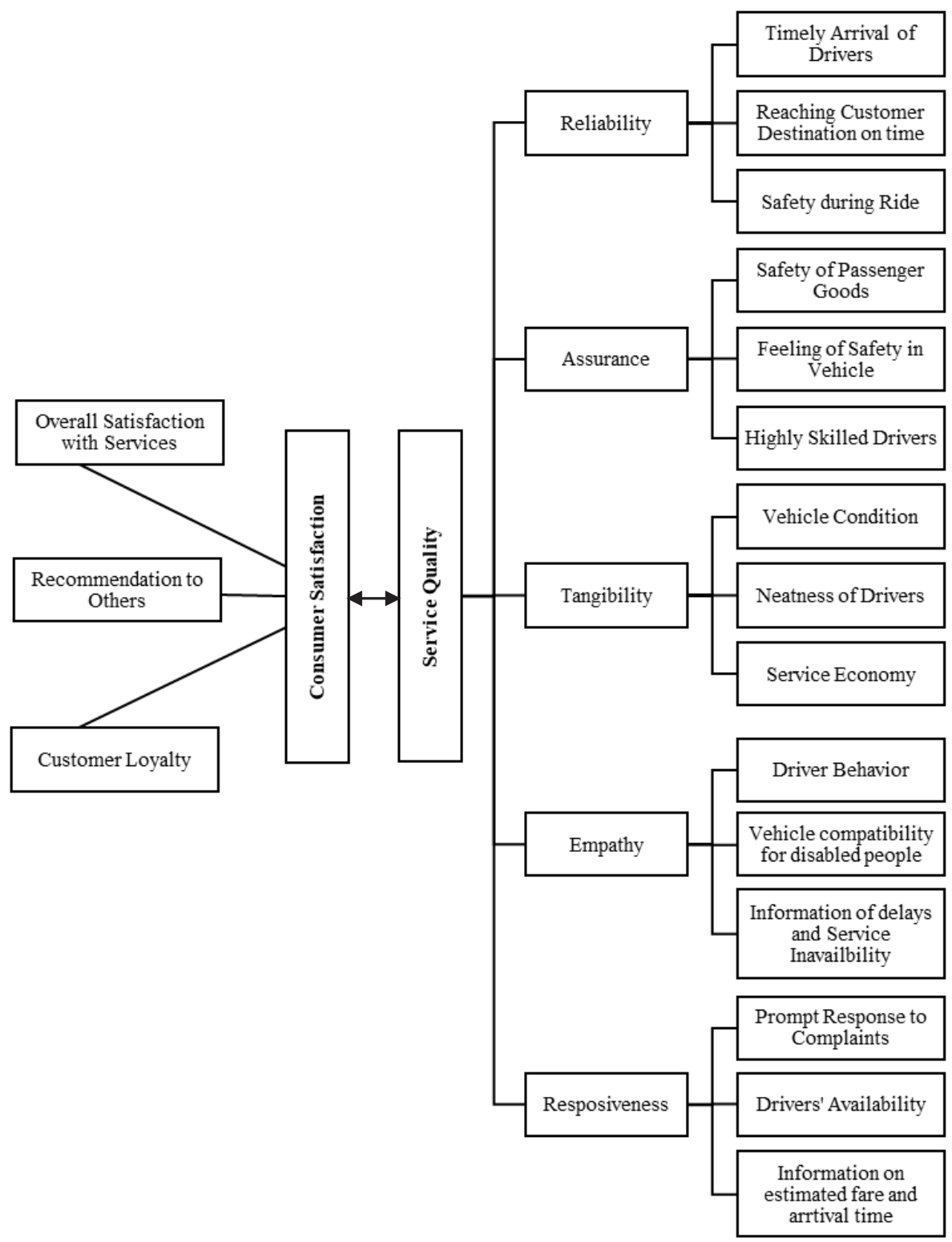

Fig. 1.

SERVQUAL Model Dimensions 


\section{Analysis, Results and Discussion}

A pilot study was carried out on 30 respondents for a reliability test. Table 1 presents Reliability test outcome. When all six variables (i.e. five service quality parameters and consumer satisfaction) were incorporated in the reliability test, the "Cronbach's Alpha" value came out to be 0.906 which was close to 1.000 indicating a strong consistency between contents of the questionnaire. "Cronbach's
Alpha” values of Table 1 showed that deleting any of the six parameters from the statistical analysis would decrease the Cronbach's Alpha value below 0.906 thereby decreasing its reliability. According to (Olorunniwo et al., 2006), if the Cronbach's alpha coefficient has a value of more than 0.70 ; the adopted questionnaire has acceptable reliability. The reliability test results depicted acceptable consistency and reliability of the questionnaire to be used for the survey.

Table 1

Reliability Test Results

\begin{tabular}{|c|c|}
\hline Variables & Cronbach's Alpha Value \\
\hline Reliability & 0.893 \\
\hline Assurance & 0.869 \\
\hline Tangibility & 0.903 \\
\hline Empathy & 0.901 \\
\hline Responsiveness & 0.880 \\
\hline Consumer Satisfaction & 0.890 \\
\hline
\end{tabular}

The demographic results of all 268 respondents are summarized in Figure 2. $64 \%$ of the respondents were male while $36 \%$ comprised of females. A high percentage of male ridesharing users showed that in the selected region, more males used ridesharing services as compared to female passengers. It is to be noted here that in third world countries, the problems of sexual harassment and insecurity for female passengers are very significant. Moreover, passengers belonging to the age group of 18-25 years and 26-35 years were found to be in majority among ridesharing users whereas the percentage of passengers belonging to age groups of 36-45years, $45-55$ years and above 55 years, were $15 \%, 7 \%$, and $6 \%$ respectively. A high percentage of youngsters among users of ridesharing apps may have been highlighted based on the fact that in third world countries like Pakistan, mostly youngsters possess proper know-how of information technology- based applications and smartphones. Government and private employees were found to be the most dominant consumers of ridesharing services having a total share of $50 \%$ of the total participants of the survey. The percentage of students came out to be $28 \%$ followed by entrepreneurs and "not working” people contributing $10 \%$ and $12 \%$ of the total sample size of the research study, respectively. The demographic results of the survey revealed that more than $43 \%$ of the users of ridesharing applications belonged to an annual income group of less than $€ 1,500$. People belonging to an annual income group of $€ 3,000$ to $€ 4,500$ and $€ 4,500$ to $€ 6,000$ were found to be the second most dominant users of ridesharing applications comprising of $17 \%$ of ridesharing users. Statistical results revealed that Careem was the favorite ridesharing company of $51 \%$ of the total ridesharing users whereas the remaining $49 \%$ of consumers preferred to travel by Uber. It 
can be inferred from this result that both of the ridesharing applications are equally famous among ridesharing consumers in the selected city. The survey results also indicated that majority of the ridesharing passengers, utilize ridesharing services rarely or once a week. The percentage of regular or frequent ridesharing users was found to be $4-14 \%$ of the total ridesharing consumers.

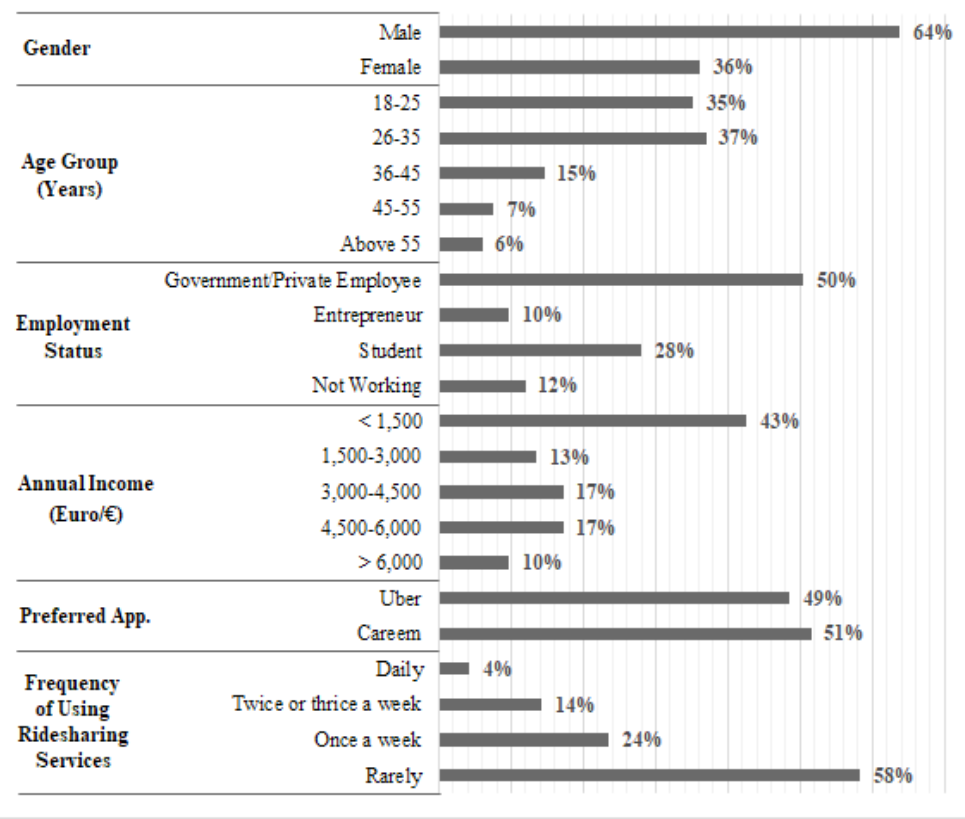

Fig. 2.

Demographic Results of Survey

Pearson Correlation Analysis was performed on the survey results using SPSS. All the values of Pearson correlation coefficients were found to be positive, as shown in Table 2 which depicted a positive correlation between consumer satisfaction and other five service excellence parameters. Responsiveness had a correlation coefficient value of 0.631 which showed its robust correlation with consumer satisfaction. Its $\mathrm{p}$-value was also less than 0.05 proving its significantly strong correlation with consumer satisfaction. By improving the performance measures of responsiveness such as prompt response to customer's complaints along with driver availability, consumer satisfaction can be increased hence responsiveness was found to be of vital importance in determining consumer satisfaction. The correlation coefficient value for assurance was 0.608 and p-value was less than 0.05 which rendered it significantly and strongly correlated to consumer satisfaction. The result of correlation analysis showed that assurance as determined from the safety of passengers, that of goods and high skill set of drivers also proved to be a significant contributor to consumer satisfaction. 
Reliability was also moderately correlated to consumer satisfaction with a correlation coefficient value of 0.499 . Its $\mathrm{p}$-value was less than 0.05 which showed the significant relationship of reliability with consumer satisfaction. The correlation analysis moderately and significantly correlated tangibility with consumer satisfaction with a correlation coefficient value of 0.478 and p-value of less than 0.05 , showing approximately the same correlation with consumer satisfaction as that of reliability. Correlation analysis of reliability and tangibility with consumer satisfaction resulted in inference that associated performance measures like arrival of ridesharing drivers on time, timely arrival of passengers on destination, safety during services, good condition of vehicles, neatness of the drivers and service economy in form of reduced fares as compared to other transport options, played a moderately important role in determining the overall consumer satisfaction and by increasing or improving all these factors, the consumer satisfaction of ridesharing customers would increase.

Earlier in the research, empathy was assessed by driver behavior with shared ride passengers, compatibility of vehicles for disabled personals and availability of information related to delays and unavailability of services prior to booking a ride. Table 2 shows that empathy had a correlation coefficient value of 0.474 with consumer satisfaction, almost the same as that of tangibility. Its p-value was less than 0.05 which made the correlation of empathy and consumer satisfaction, a significant one. An important observation which was inferred from this correlation was that although good driver behavior with passengers, availability of vehicles compatible with disabled passengers and informatory services like notifications of delays, etc. did not play strong rather a moderate role in determining consumer satisfaction. The research results also indicated that the majority of the vehicles used by TNCs were not assessable by disabled passengers.

\section{Table 2}

Pearson Correlation Analysis Results

\begin{tabular}{|c|c|c|c|c|c|c|}
\hline \multicolumn{7}{|c|}{ Pearson Correlation } \\
\hline Variable(s) & $\begin{array}{c}\text { Consumer } \\
\text { Satisfaction }\end{array}$ & Reliability & Assurance & Tangibility & Empathy & Responsiveness \\
\hline $\begin{array}{c}\text { Consumer } \\
\text { Satisfaction }\end{array}$ & 1.000 & 0.499 & 0.608 & 0.478 & 0.474 & 0.631 \\
\hline Reliability & 0.499 & 1.000 & 0.610 & 0.309 & 0.340 & 0.393 \\
\hline Assurance & 0.608 & 0.610 & 1.000 & 0.391 & 0.314 & 0.382 \\
\hline Tangibility & 0.478 & 0.309 & 0.391 & 1.000 & 0.477 & 0.525 \\
\hline Empathy & 0.474 & 0.340 & 0.314 & 0.477 & 1.000 & 0.402 \\
\hline Responsiveness & 0.631 & 0.393 & 0.382 & 0.525 & 0.402 & 1.000 \\
\hline \multicolumn{7}{|c|}{ Sig. (1-tailed) } \\
\hline Variable(s) & $\begin{array}{c}\text { Consumer } \\
\text { Satisfaction }\end{array}$ & Reliability & Assurance & Tangibility & Empathy & Responsiveness \\
\hline $\begin{array}{c}\text { Consumer } \\
\text { Satisfaction }\end{array}$ &. & 0.000 & 0.000 & 0.000 & 0.000 & 0.000 \\
\hline Reliability & 0.000 &. & 0.000 & 0.000 & 0.000 & 0.000 \\
\hline Assurance & 0.000 & 0.000 &. & 0.000 & 0.000 & 0.000 \\
\hline Tangibility & 0.000 & 0.000 & 0.000 &. & 0.000 & 0.000 \\
\hline Empathy & 0.000 & 0.000 & 0.000 & 0.000 &. & 0.000 \\
\hline Responsiveness & 0.000 & 0.000 & 0.000 & 0.000 & 0.000 & \\
\hline
\end{tabular}


Multiple regression analysis was carried out on the six variables. Consumer satisfaction was taken as dependent variable whereas reliability, assurance, tangibility, empathy, and responsiveness were taken as independent variables. The regression analysis was carried out in SPSS using the "stepwise" method. Tangibility and reliability were excluded from the regression analysis since the two independent variables were making an insignificant contribution to the model. Table 3 shows the statistics of excluded variables. The p-value of tangibility was 0.480 and that of reliability was 0.236 , both were greater than alpha value i.e. 0.05 hence making these variables less significant. "Beta In" column states the value of regression coefficients if these two variables would have been included in the regression model.

Table 3

Excluded Variables Statistics

\begin{tabular}{|c|c|c|c|}
\hline Excluded Variables & Beta In & T & Sig. \\
\hline Tangibility & 0.036 & 0.708 & 0.480 \\
\hline Reliability & 0.061 & 1.187 & 0.236 \\
\hline
\end{tabular}

The results of the ANOVA are summarized in Table 4. According to ANOVA results, $F$ $(3,264)=123.426, \mathrm{P}<0.05$. In simple words, the remaining three independent variables were significant predictors of the dependent variable i.e. consumer satisfaction. The high $F$ value of 123.426 indicated a joint significant effect of assurance, empathy, and responsiveness in predicting consumer satisfaction.

Table 4

ANOVA Results

\begin{tabular}{|c|c|c|c|c|c|}
\hline Model & Sum of Squares & Df & Mean Square & F & Sig. \\
\hline Regression & 23.141 & 3 & 7.714 & 123.426 & $0.000 \mathrm{a}$ \\
\hline Residual & 16.499 & 264 & .062 & - & - \\
\hline Total & 39.641 & 267 & - & - & - \\
\hline \multicolumn{7}{|c|}{ a. Predictors: (Constant), Responsiveness, Assurance, Empathy } \\
\hline
\end{tabular}

The results of the final regression model are recorded in Table 5. The R-value of 0.764 showed a positive and high correlation of consumer satisfaction with responsiveness, assurance, and empathy.
The R-square value of 0.584 indicated that the prediction model was accounted for approximately $58.4 \%$ of the variance of consumer satisfaction of the ridesharing industry.

\section{Table 5}

Multiple Regression Model

\begin{tabular}{|c|c|c|c|c|}
\hline Model & R & R Square & Adjusted R Square & $\begin{array}{c}\text { Std. Error of the } \\
\text { Estimate }\end{array}$ \\
\hline 1 & $0.764^{\mathrm{a}}$ & 0.584 & 0.579 & 0.24999 \\
\hline \multicolumn{5}{|c|}{ a. Predictors: (Constant), Responsiveness, Assurance, Empathy } \\
\hline
\end{tabular}


Table 6 shows the values of regression coefficients. Analysis of these tables showed that assurance, empathy, and responsiveness, apart from jointly playing a significant role in the model, were contributing significantly, individually as well. The "Sig." column of Table 6 communicated the same since the p-value of three variables was less than 0.05 . Assurance predicted the consumer satisfaction to a higher extent as its regression coefficient was 0.268 . Consumer satisfaction was predicted to a less extent as compared to assurance, by responsiveness (regression coefficient $=0.262$ ). Least contribution in predicting consumer satisfaction in the ridesharing industry of Pakistan was made by empathy, having an unstandardized coefficient value of 0.112 .

\section{Table 6}

Multiple Regression Coefficients

\begin{tabular}{|c|c|c|c|c|c|}
\hline \multirow{2}{*}{$\begin{array}{c}\text { Regression Equation } \\
\text { Variables }\end{array}$} & \multicolumn{2}{|c|}{ Unstandardized Coefficients } & \multirow{2}{*}{$\begin{array}{c}\begin{array}{c}\text { Standardized } \\
\text { Coefficients }\end{array} \\
\text { Beta }\end{array}$} & \multirow{2}{*}{$\mathbf{T}$} & \multirow{2}{*}{ Sig. } \\
\hline & B & Std. Error & & & \\
\hline (Constant) & 1.592 & 0.124 & - & 12.822 & 0.000 \\
\hline Assurance & 0.268 & 0.030 & 0.395 & 9.021 & 0.000 \\
\hline Empathy & 0.112 & 0.026 & 0.187 & 4.235 & 0.000 \\
\hline Responsiveness & 0.262 & 0.029 & 0.404 & 8.913 & 0.000 \\
\hline
\end{tabular}

In a similar research study conducted on minicab taxi services of Cape Coast, Ghana, the value of $\mathrm{R}$-square in the regression model was recorded as 0.539 (Horsu \& Yeboah, 2015). Khuong and Dai (2016) studied the factors affecting customer satisfaction and customer loyalty on local taxi companies in Vietnam using reliability, responsiveness, comfort, price and information using regression model, yielding an $\mathrm{R}$-square value of 0.596. Consumer satisfaction research study carried out on ridesharing services of Malaysia using service quality factors i.e. tangible, reliability, price and promotion, the regression model resulted in an R-square value of 0.647 (Balachandran and Hamzah, 2017). In India, the online cab industry was evaluated for consumer satisfaction by assessing service quality variables in light of SERVQUAL Model. The results were formulated into a regression model with associated R-square value of 0.591 (Sharma \& Das, 2017).
In Pakistan, driver behavior and price affordability were coupled with other service quality dimensions to assess the existing consumer satisfaction among users of mobile app-based taxi services. The analytical model formed in this study had an R-square value of 0.565 (Rasheed et al., 2018). A similar study on mobile apps-based taxi services of Saudi Arabia concluded into a model associated with an R-square value of 0.269 (Sajid et al., 2018). In light of this discussion, the R-square value of this research study i.e. 0.584 , was found to be comparable with studies of the similar sort conducted in the past.

Considering the results of multiple regression analysis, the regression equation for this research study was formulated as under Eq.1:

$Y=1.592+0.268 X_{1}+0.112 X_{2}+0.262 X_{3}$

Where:

$\mathrm{Y}=$ Consumer Satisfaction; 
$\mathrm{X}_{1}=$ Assurance;

$\mathrm{X}_{2}=$ Empathy;

$\mathrm{X}_{3}=$ Responsiveness.

The regression equation showed that upon increasing assurance, empathy, and responsiveness, consumer satisfaction would also increase and vice versa. Also, for a single unit increase in assurance, empathy, and responsiveness, consumer satisfaction would increase by $0.268,0.112$ and 0.262 units if only single independent variable under consideration was changed while keeping the others constant. It was evident from the regression model that assurance was the most dominant variable predicting consumer satisfaction followed by responsiveness and empathy.

\section{Conclusions}

Since the introduction of ridesharing applications like Uber and Careem in Pakistan, a study was needed to assess consumer satisfaction using service quality parameters. The purpose of the study was to determine the influence of service quality factors such as reliability, assurance, tangibility, empathy, and responsiveness on consumer satisfaction. The service quality parameters opted for this research study were taken from the SERVQUAL Model. It is also known as RATER, named after its five-service quality dimensions such as reliability, assurance, tangibility, empathy, and responsiveness. The correlation analysis showed that all five service excellency factors were strong to moderately correlated with consumer satisfaction.

According to the results of multiple regression analysis, out of five service excellency factors, only assurance, empathy and responsiveness were strong and significant predictors of consumer satisfaction. In other words, by improving driver behavior with the customers, driving skills of the drivers, safety of passengers' goods and increasing the feeling of safety during rides can enhance consumer satisfaction. Moreover, informing passengers of delays and unavailability of ridesharing services before booking of rides along with a prompt response to passengers' complaints and the ready availability of ridesharing drivers can also result in increased consumer satisfaction. Tangibility and reliability were excluded from the regression analysis based on their corresponding insignificant contribution in predicting consumer satisfaction. The results concluded that factors such as vehicle condition, neatness of driver, service economy, the timely arrival of drivers on pin location and on-time completion of the journey, do not significantly influence consumer satisfaction. In Pakistan, such a statement could be true based on the unavailability of alternatives such as local air-conditioned taxis and other economical information technology-based services.

This research study also concluded that the majority of the ridesharing service users were males belonging to the age group of 18 to 35 years. Most of the ridesharing users comprised of government and private employees. The users took benefit of ridesharing apps on rare occasions. An important discovery of this study was that both Uber and Careem were equally famous among consumers.

\section{Limitations and Future Scope of Study}

This research study was only carried out on respondents using a mode of transport as cars/ sedans for ridesharing purposes. However, in Pakistan, as of now, there are other modes of transportation introduced by ridesharing firms as well i.e. rickshaws and motorcycles. Since this research model is only limited to 
ridesharing on cars so it is recommended to carry out another research study to take into account the impact of service quality of other transportation modes of ridesharing services on consumer satisfaction.

Better sampling techniques can be utilized to avoid sampling bias. The results of this research study can be applied to all those areas having similar physical and economic conditions as that of the city under consideration. It is recommended that some other studies of a similar sort be carried out to further authenticate the results of this model in different geographical areas. Further, the study can be carried out by adding more variables in the regression model affecting consumer satisfaction which may result in the identification of performance measures having a significant impact on consumer satisfaction. It will also assist the ridesharing service providers in understanding their customers' needs in a better way. Furthermore, ridesharing services operating in can make use of this research study to improve their quality of service.

\section{Acknowledgements}

The authors acknowledge the cooperation and assistance of ridesharing companies' staff members for providing up to date information related to the research subject. The authors also thank transport department officials for their contribution in research study. Lastly, the authors would like to thank all the supervisors in assisting throughout this comparative study and research.

\section{References}

Ahmed, S.; Burki, S. 2018. Empirical Analysis of Ride Sharing Applications in Karachi, International Journal of Experiential Learning \& Case Studies 2(2): 40-49.
Balachandran, I.; Hamzah, I.B. 2017. The Influence of Customer Satisfaction on Ride-Sharing Services in Malaysia, International Journal of Acounting, Business and Management 5(2): 184-196.

Buttle, F. 1996. SERVQUAL: review, critique, research agenda, European Journal of Marketing 30(1): 8-32.

Careem. 2019. Uber to acquire Careem to expand the greater Middle East regional opportunity together. Available from Internet: <https://www.careem.com/public-assets/ landing-page-docs/Uber\%20Careem\%20-\%20Press\%20 Release.pdf $>$.

Caro, L. M.; Garcia, J. A. M. 2007. Measuring perceived service quality in urgent transport service, Journal of Retailing and Consumer Services 14(1): 60-72.

Government of Alberta. 2019. Transportation Network Companies - Frequently Asked Questions. Available from Internet: <http://www.transportation.alberta. $\mathrm{ca} /$ documents/TransportationNetworkCompanyFAQs. pdf $>$.

Horsu, E. N.; Yeboah, S. T. 2015. Influence of service quality on customer satisfaction: A study of minicab taxi services in Cape Coast, Ghana, International Journal of Economics, Commerce and Management 3(5): 1451-1464.

Khan, A.W.; Jangid, A.; Bansal, A.; Maruthappan, S.; Chaudhary, S.; Tyagi, V.; Rao, P.H. 2016. Factors Affecting Customer Satisfaction in the Taxi Service Market in India, Journal of Entrepreneurship \& Management 5(3): 46-53.

Khuong, M. N.; Dai, N. Q. 2016. The Factors Affecting Customer Satisfaction and Customer Loyalty - A Study of Local Taxi Companies in Ho Chi Minh City, Vietnam, International Journal of Innovation, Management and Technology 7(5): 149-162.

Kotler, P.; Keller, K. 2006. Marketing Management. 12th Edition, Prentice Hall, Upper Saddle River. 816 p. 
Kotrlik, J.W.; Higgins, C.C. 2001. Organizational research: Determining appropriate sample size in survey research appropriate sample size in survey research, Information Technology, Learning, and Performance Journal 19(1): 43-50.

Kumar, P. K.; Kumar, N. R. 2016. A Study on Factors Influencing the Consumers in Selection of Cab Services, International Journal of Social Science and Humanities Research 4(3): 557-561.

OECD. 2018. Taxi, ride-sourcing and ride-sharing services. Available from Internet: <https://one.oecd. org/document/DAF/COMP/WP2(2018)1/en/pdf >.

Oliver, R. L. 1980. A cognitive model of the antecedents and consequences of satisfaction decisions, Journal of Marketing Research 17(4): 460-469.

Oliver, R. L.; Balakrishnan, P. S.; Barry, B. 1994. Outcome satisfaction in negotiation: A test of expectancy disconfirmation, Organizational Behavior and Human Decision Processes 60(2): 252-275.

Olorunniwo, F.; Hsu, M. K.; Udo, G. J. 2006. Service quality, customer satisfaction, and behavioral intentions in the service factory, Journal of Services Marketing 20(1): 59-72.

Parasuraman, A.; Zeithaml, V. A.; Berry, L. L. 1985. A conceptual model of service quality and its implications for future research, Journal of Marketing 49(4): 41-50.

Parasuraman, A.; Zeithaml, V. A.; Berry, L. L. 1988. SERVQUAL: A multiple-item scale for measuring consumer perception of service quality, Journal of Retailing 64(1): 12-40.

Patterson, P. G. 1993. Expectations and product performance as determinants of satisfaction for a high involvement purchase, Psychology \& Marketing 10(5): 449-465.
Rasheed, R.; Mazhar, F.; Shahid, M. 2018. Mobile appbased Taxi Services and Customer Satisfaction: An empirical review form Lahore city, Pakistan, Internationa Journal of Economics, Commerce and Management 6(5): 330-340.

Sajid, A.; Ayid, A.M.; Majed, A.D.; Faisal, A.M. 2018. Taxi Services in Saudi Arabia through Mobile Apps: An Empirical Investigation, Research Journal of Finance and Accounting 9(4): 95-104.

Salameh, A. A.; Hassan, S. B. 2015. Measuring service quality in M-commerce context: a conceptual model, International Journal of Scientific and Research Publications 5(3): 1-9.

Saravanan, R.; Rao, K. 2007. Measurement of service quality from the customer's perspective-an empirical study, Total Quality Management and Business Excellence 18(4): 435-449.

Sharma, K.; Das, S. 2017. Service quality and customer satisfaction with special focus on the online cab Industry in India, International Journal of Business and Management 12(7): 192-200.

Silalahi, S. L. B.; Handayani, P. W.; Munajat, Q. 2017. Service quality analysis for online transportation services: Case study of GO-JEK, Procedia Computer Science 124: 487-495.

Spreng, R. A.; Mackoy, R. D. 1996. An empirical examination of a model of perceived service quality and satisfaction, Journal of Retailing 72(2): 201-214.

Su, S.; Huang, Y. 2016. Customized Marketing-An approach for SMEs to improve customer satisfaction: The case of firms operating in the shipping industry. Master Thessis. Halmstad University. 82 p.

Wallsten, S. 2015. The competitive effects of the sharing economy: how is Uber changing taxis, Technology Policy Institute 22: 1-21. 